This item was submitted to Loughborough's Research Repository by the author.

Items in Figshare are protected by copyright, with all rights reserved, unless otherwise indicated.

\title{
Macro and micro ergonomic outcomes in healthcare: unravelling the relationship between patient handling performance and safety climate
}

PLEASE CITE THE PUBLISHED VERSION

http://dx.doi.org/10.1080/21577323.2014.989338

\section{PUBLISHER}

(C) Taylor \& Francis

\section{VERSION}

AM (Accepted Manuscript)

\section{PUBLISHER STATEMENT}

This work is made available according to the conditions of the Creative Commons Attribution-NonCommercialNoDerivatives 4.0 International (CC BY-NC-ND 4.0) licence. Full details of this licence are available at: https://creativecommons.org/licenses/by-nc-nd/4.0/

\section{LICENCE}

CC BY-NC-ND 4.0

\section{REPOSITORY RECORD}

Fray, Mike, Patrick Waterson, and Colin Munro. 2019. "Macro and Micro Ergonomic Outcomes in Healthcare: Unravelling the Relationship Between Patient Handling Performance and Safety Climate". figshare. https://hdl.handle.net/2134/18936. 


\section{Macro and Micro Ergonomic Outcomes in Healthcare: Unravelling the Relationship between Patient Handling Performance and Safety Climate}

Mike Fray ${ }^{1}$, Patrick Waterson and Colin Munro

Loughborough Design School, Loughborough University Loughborough, UK. LE11 3TU

${ }^{1}$ Corresponding Author:

Dr Mike Fray

Loughborough Design School, Loughborough University

Loughborough, Leicestershire, UK. LE11 3TU

E-mail: M.J.Fray@lboro.ac.uk

Telephone: +44 (0)1509 228168

Fax: +44 (0)1509 223940 


\section{Macro and Micro Ergonomic Outcomes in Healthcare: Unravelling the Relationship between Patient Handling Performance and Safety Climate}

Occupational Considerations: The management of risks surrounding patient handling activities continues to be an important factor in healthcare organisations. A great deal of research has been undertaken to investigate best practices for physical transfers and equipment provision, yet there is less research adopting an organisational systems approach to this problem. In this paper we compare two methods for assessing safety climate and patient handling safety performance and argue that a multi-level (mesoergonomic) interpretation of the relationship between the two affords insights into the safety of the system as a whole.

\section{Technical Abstract:}

Background/Rationale: Karsh et al (2014) proposed a model for developing cross-level ergonomics investigations which clarified the inclusion of micro, macro and meso level factors to any organisational investigation. In this paper we explore the use of this model to create a clearer understanding of the healthcare specific activities that surround the management of patient handling functions within a neurological rehabilitation setting.

Methods: Six acute medical wards in a large UK teaching hospital were used to explore the relationship between patient handling, as part of a complex socio-technical healthcare system, and safety climate. Data were collected using the TROPHI (Tool for Risk Outstanding in Patient Handling Interventions) and SCS (Safety Climate Survey) and analysed using descriptive statistics and Spearman's Rank Correlation.

Results: A variety of results highlighted strengths and weaknesses in safety climate and patient handling risks. Significant correlations were found between TROPHI Safety Climate scores and the SCS Overall Mean.

Conclusion: These results suggest that the differences between scores across a variety of measures indicate that a wider range of data may be required to best represent a measure of safety climate in this occupational setting.

Keywords: Patient handling, Safety climate, Meso-ergonomics, Macro -ergonomics, healthcare 


\section{Introduction}

The last few years have seen an explosion of interest in applying theories and concepts drawn from Human Factors and Ergonomics (HFE) to healthcare and patient safety. A wide variety of topics have been investigated in depth, including the design and implementation of health information technologies (Karsh et al., 2010; Waterson, 2013), medication safety (Flynn, 2007), and infection prevention and control (Waterson, 2009; Alvarado, 2007). These studies span a range of work covering all of the traditional components of HFE including organisational, cognitive and physical ergonomics (IEA, 2009). In addition, a number of macroergonomic systems models have been developed in order to provide further insights into the relationship between work organisation, technology, work tasks and environmental and organisational variables (e.g., Vincent et al., 1998, Carayon et al., 2006; Holden et al., 2013). More recently, Waterson (2009), Karsh et al., (2014), Wilson (2014) and Ko and Bindman (in press) have argued the need for studies which examine microand macroergonomics across a number of systems levels, that is, work which seeks to measure variables at individual-team or team-organisational levels and examine their inter-relationship. In this paper, we describe a case study which sought to examine in greater depth the relationship between patient handling practices (a traditional focus of inquiry within occupational ergonomics) and measures of patient safety climate (normally seen as a macroergonomics concern). In particular, we sought to explore some of the possible causal mechanisms which might link safety climate and patient handling. Some of these mechanisms may be 'hidden' from view given, for example, only one type of investigation (e.g., a focus of safety climate alone). The adoption of what Karsh et al., (2014) called a 'mesoergonomic' stance towards our study design and data collection might help to facilitate identification of these mechanisms and prompt further, more focused investigation in later studies. In what follows, we briefly review research in both these areas of healthcare HFE, before moving on to describing the details of the case study.

\subsection{Patient safety climate (PSC)}


Patient safety climate (PSC) is sometimes defined as "the product of individual and group values, attitudes, perceptions, competencies, and patterns of behaviour that determine the commitment to, and the style and proficiency of, an organization's health and safety management” (Nieva and Sorra, 2003 pii18). The term 'safety climate' is often used interchangeably with 'safety culture', however in this paper we follow Guldenmund (2000, p. 222) and refer to climate as “denoting attitudes to safety within an organisation" and culture as a looser collection of "strong convictions or dogmas underlying safety attitudes”. Healthcare organisations, such as hospitals, with a positive safety climate are often characterised as having good communication and levels of trust between staff, managers, patients and other stakeholders in the overall healthcare system. Likewise, a positive safety climate is associated with widely shared perception of the importance and value of safety and the prevention of error.

The first safety climate tools designed specifically for use in healthcare began to appear around 2004. Many of these tools are in the form of survey instruments or questionnaires, the two most well-known being the Hospital Survey on Patient Safety Culture (HSPSC) developed by the US Agency for Healthcare Research and Quality (AHRQ) and the Safety Attitudes Questionnaire (SAQ - Sexton et al., 2006). A number of other tools exist, some of which aim to target specific aspects of safety climate (e.g., leadership behaviours, communication during surgical handover - World Health Organization, 2013 - see Itoh et al., 2012 for an extensive review of these). These tools have been applied across a wide range of healthcare contexts and healthcare systems around the world and the available evidence suggests that interest in their use is expanding (Halligan and Zecevic, 2011). Typically PSC instruments are made up of a number of dimensions with specific questions covering, for example: staff perceptions of safety; management and leader support for safety; staffing levels; and attitudes towards mistakes and error. In addition to their psychometric properties (i.e., the extent to which they actually measure healthcare safety), a number of criticisms and suggestions for improvements to PSC instruments and tools have been made in the last few years. Chief amongst these has been the need to carry out studies which relate PSC measurements to other aspects of safe 
behaviour and additional patient safety variables (e.g., incidence of error, patient outcomes - Flin , 2007).

\subsection{Patient handling performance}

Patient handling $(\mathrm{PH})$ is part of the complex socio-technical healthcare system and has the potential to impact on both staff and patient safety. Outcomes from poor PH interventions range from discomfort, pain, and emotional distress, to musculoskeletal injuries, pressure sores, and death (Alexander, 2011). Internationally, the activities of manual handling in the healthcare sector have received much attention and have developed markedly. Much of the early research centred on the microergonomics information of biomechanics and physical workload and its relationship to musculoskeletal disorders (e.g. Knibbe and Friele 1999, Marras et al. 1999). As the level of application and understanding in the field developed a systems approach including organisational implications and intervention strategies was also adopted in best practice guidelines (ANA 2012, NBE 2010, Smith, ed., 2011). This approach creates complex workplace intervention programmes which cover a full range of ergonomics issues from individual to organisational and industry level (Carayon et al., 2006).

The development of multifaceted ergonomics interventions to improve the control of risks associated with the movement of people in all care settings has been under-researched. The growing body of evidence (e.g. Nelson et al., 2006) show positive returns, but the relationship with patient injury, accident and health related outcomes remains difficult to ascertain (Trinkoff et al., 2011, Nelson et al., 2008). Measuring of the performance of these complex interventions has been approached using various methods (Fray 2010) but the comparison of measures is difficult. The analysis of PH interventions and outstanding risk has been considered using individual PH risk assessments and plans, physical environment risk assessments, individual observational tools for specific PH tasks (posture, biomechanical), organisational / management structure audit tools, and financial models of assessment. Although some of these methods have been used for intervention trials and evaluated in validation studies, there is very little overlap in the risks measured. These studies have shown a 
greater understanding for evaluating outcomes of $\mathrm{PH}$ interventions, but the difficulty of comparing measures, results and recommendations across interventions remains (Fray and Hignett, 2013). The specific performance measures reported utilise different content and different approaches. The range of measures included; the level or volume of the intervention; outcome metrics; musculoskeletal injury, discomfort or absence; observations of methods or techniques against risk ratings etc.. The Tool for Risks Outstanding in Patient Handling Interventions (TROPHI) (Fray and Hignett, 2013, ISO TR 12296, 2012) scores 12 performance measures including organisational, staff and patient outcome metrics and so offers potential to compare all intervention types (See TROPHI Table 1).

\subsection{Aim}

The current case study uses the Karsh et al. (2014) meso-ergonomics framework to investigate the relationships between micro and macro-ergonomics outcome measures when applied to the activities of patient handling in a neurological rehabilitation setting. Specifically, the across-levels methodology (meso) will compare the relationships between macro issue of climate and traditionally micro levels of musculoskeletal injury and physical transfer methods.

\section{A framework for investigating the relationship between safety climate and patient handling}

Karsh et al. (2014) present a framework for what they termed 'mesoergonomic inquiry', where 'mesoergonomics' is defined as “an open systems approach to ergonomic theory and research whereby the relationship between variables in at least two different levels or echelons is studied, where the dependent variables are human factors and ergonomic constructs” (Karsh, 2006). The framework consists of four steps: (1) establishing the purpose of the investigation; (2) selecting a group of HFE variables to be investigated; (3) deciding what type of analysis is appropriate i.e., micro-, meso-, or exclusively macroergonomic; and, (4) interpreting the findings from the study in order to examine whole system, cross or multiple levels of analysis. Figure 1 outlines the main stages in using the framework. 


\subsection{Applying the framework}

The Karsh et al (2014) model described a methodology that can be used to explore these multi and cross level situations to help improve understanding. How, the present case study interpreted this methodology as outlined in the four steps below.

\subsubsection{Step 1: What is the purpose of the investigation?}

This investigation explored the assumption that safety climate is a powerful influence on safety performance in healthcare by comparing the measures of TROPHI (Fray and Hignett, 2013) and the Safety Climate Survey (SCS, IHI, 2012). Best practice guidelines (e.g. ANA 2012, Smith et al 2011) all suggest that organisational systems creating positive safety culture and climate should support the patient handling performance of an organisation. This investigation aimed to explore that relationship and add to the understanding of how the micro- and macroergonomics levels interact.

\subsubsection{Step 2: Select the HFE variables under consideration.}

The function of this step is to evaluate the possible differences in the responses to organisational structures and systems. In this study, the effects were measured relative to the conditions in the location that were in place at the time of the survey. The following independent and dependent variables were considered:

Independent variables: Ward types, patient workload and demands, implemented systems for organisational management of patient handling risks, and organisational structures.

Dependent variables: These included the full range of performance measures describing patient handling risk management; safety climate, musculoskeletal health across the location, competence and compliance with best practice, absence and ill health, quality of care, incidents and accidents, 
psychological well-being of the staff, the management of patient conditions, perception of patient handling by patients, the relative exposure to risks against best practice, injuries to patients, and the financial impact on the organisation.

\subsubsection{Step 3: Type of HFE investigation}

The Karsh et al (2014) model suggested micro, macro or meso ergonomics investigations can be selected as the focus of the investigation. In this application, the cross level (mesoergonomics) relationships were investigated to obtain a better understanding about those relationships and how the different outcome measures interact and co-contribute to the overall measure of safety performance in the patient handling system.

\subsubsection{Step 4: What type of relationships exist?}

Fray and Hignett (2013) indicated that, from the development of definitions for the TROPHI tool, created from international focus group data, there was a cascade relationship between the outcomes measured (See Table 1). Safety climate - including management commitment, the development of policy, protocols and organisationally led responses to the issues - was identified as a driver for all the sections. The overall measure of safety climate would impact upon the behaviour of individuals, so measures which calculated their actions, errors or compliance would follow the organisational impact (e.g. did staff follow best patient handling practice (Line 3 - Table 13)). This, in turn, would be seen in the measures of the effects on individuals (e.g. musculoskeletal absence (Line 4 - Table 1) and patient feedback (Line 9 - Table 1))_. Only when all the effects had cascaded down would the financial evaluation be seen in the form of return on investment. In summary, the work of Fray and Hignett (2013) suggested that safety climate affects group behaviour, which in turn can be measured as changes to individuals, and after all changes have been observed the effects can be seen in financial outcomes. This investigation specifically explores this relationship (Figure 2). 

and locations (A-F) have been withheld. achieved.

251 different sites.

\section{Case Study}

Data collection was conducted in a large city-based NHS Acute Health Trust in the UK. Each of the six wards delivered care to patients that had suffered a stroke, and each had levels of acute condition management through to longer term rehabilitation requirements. Though centrally managed within the Trust, five different sites were covered in the sample. For the purposes of anonymity the names

\subsection{Study Structure}

The study was a single cohort survey with all locations visited for a single data collection. Data for TROPHI and SCS were recorded in all areas and the process and results were compared. Data collection training using TROPHI was conducted by the developer (MF) with the researcher (CM) at a pilot ward within the host organisation. This training included observing patient handling manoeuvres and interviewing the manager, followed by a debriefing session to ensure TROPHI standards were

Six Stroke Units (A-F) were selected due to the similarity in medical condition and wide range of patient handling activities. All areas were considered to have a high level of varied PH activity, use of equipment, documentation and techniques which would require staff to assess the patients’ manual handling requirements. The units were spread over a city-wide geographical location and on five 
The study recorded the responses for each ward from all staff in each unit, including qualified nurses and all health-care workers. Staff questionnaires were allocated to all, excluding those on maternity leave and long term sick. Observations of the patient handling tasks were completed using a convenience sample of the tasks completed during the survey visit.

\subsection{Data Collection}

The ward managers of the 6 participating wards/units were contacted to explain the nature of the study and that relevant permissions had been attained and preparation for the trial completed. One week prior to data collection managers were provided with information to promote the study as part of the staff hand-over and as a poster for the ward information board. Managers were provided with sealed, addressed staff questionnaire envelopes with an explanatory letter (explaining the project, voluntary participation and the anonymity of individuals), and were asked to distribute them and to encourage their staff to return them to the post box provided on the ward.

The 6 areas were visited on a week day morning, to ensure patient handling activity. TROPHI data were collected during a single visit and staff were encouraged to complete the questionnaires.

Questionnaires were collected from the ward one week after the survey. Managers and staff were thanked for their cooperation. The response rate for the survey was compared against the number of whole time equivalents who were expected to staff each ward.

\subsubsection{Data Collection Tool - TROPHI}

TROPHI collects data from 4 separate survey methods and calculates 12 different performance measures. Where possible, the performance measures are based on peer-reviewed validated methods. Further explanation of the tools development can be found in Fray and Hignett (2013). These measures represent macro, meso and microergonomics measures and data are collected from organisational systems, managers, staff and patients.

Table 1. TROPHI measure definitions. 


\begin{tabular}{|l|l|}
\hline \multicolumn{1}{|c|}{ Preferred outcome } & \multicolumn{1}{|c|}{ Outcome measurement tool } \\
\hline 1 Safety Culture & $\begin{array}{l}\text { Organisational audit of safety systems reviewing risk } \\
\text { assessment and communication for patient handling }\end{array}$ \\
\hline 2 MS health & $\begin{array}{l}\text { Musculoskeletal issues in staff from staff completed Nordic } \\
\text { Questionnaire (simplified) }\end{array}$ \\
\hline 3 Competence/ Compliance & $\begin{array}{l}\text { Observational checklist (DiNO) of how the task was } \\
\text { performed and documented }\end{array}$ \\
\hline 4 Absence or staff health & $\begin{array}{l}\text { Standard absence per work population for musculoskeletal } \\
\text { injury }\end{array}$ \\
\hline 6 Accident numbers & $\begin{array}{l}\text { Ward and patient survey to evaluate care quality relative to } \\
\text { patient handling }\end{array}$ \\
\hline 7 Psychological well being & $\begin{array}{l}\text { Accident numbers and non-reporting ratios for staff } \\
\text { accidents from patient handling }\end{array}$ \\
\hline 3 Patient condition & $\begin{array}{l}\text { Survey of staff perception to assess if clinical and care } \\
\text { needs are being met }\end{array}$ \\
\hline 9 Patient perception & $\begin{array}{l}\text { Patient survey for comfort, security, fear etc at point of } \\
\text { patient handling }\end{array}$ \\
\hline 10 MSD exposure measures & $\begin{array}{l}\text { Workload calculation based on provision of equipment and } \\
\text { safe environments for patient handling tasks }\end{array}$ \\
\hline 12 Financial & $\begin{array}{l}\text { Accident numbers and non-reporting ratios for patient } \\
\text { accidents from patient handling }\end{array}$ \\
\hline & $\begin{array}{l}\text { Calculation of costs versus investment (not calculated in this } \\
\text { study) }\end{array}$ \\
\hline
\end{tabular}

TROPHI collects four data sets (Table 2). The Organisational Review and the PH Safety Climate

Audit consist of an interview with a senior member of staff in the unit and requires documented evidence of operations to support the data collection. The PH Transfer Observation requires the observer to watch and score a series of PH transfers, and collect supporting evidence from staff and patients. The Ward Survey is a self-completed questionnaire distributed to both staff and patients.

Table 2. TROPHI Data Collection Sets, Tools and Methods (Fray 2010).

\begin{tabular}{|l|l|l|}
\hline Data Set & Data Collection Tool & Data Collection Method \\
\hline $\begin{array}{l}\text { Organisational } \\
\text { Review }\end{array}$ & $\begin{array}{l}\text { 1.1 Front Sheet for TROPHI } \\
\text { 1.2 Staffing and PH workload } \\
1.3 \text { MSD rate and levels of sickness } \\
\text { absence } \\
\text { 1.4 Workload from patient dependencies } \\
1.5 \text { PH Management System } \\
1.6 \text { Cost of the intervention }\end{array}$ & $\begin{array}{l}\text { Interview with unit manager. } \\
\text { (Including Arjo Mobility } \\
\text { Gallery \& Arjo Care } \\
\text { Thermometer for 1.4) }\end{array}$ \\
\hline $\begin{array}{l}\text { Patient Handling } \\
\text { Safety Climate Audit }\end{array}$ & $\begin{array}{l}\text { 2.1 Patient Handling Safety Climate } \\
\text { Audit }\end{array}$ & $\begin{array}{l}\text { Questionnaire for unit } \\
\text { manager }\end{array}$ \\
\hline
\end{tabular}




\begin{tabular}{|l|l|l|}
\hline $\begin{array}{l}\text { Patient Handling } \\
\text { Transfer } \\
\text { Observation }\end{array}$ & $\begin{array}{l}\text { 3.1 Adapted DINO } \\
\text { 3.2 Patient Feedback } \\
\text { 3.3 Staff Feedback }\end{array}$ & $\begin{array}{l}\text { Observation of PH transfer, } \\
\text { with post transfer questions } \\
\text { for patient and staff }\end{array}$ \\
\hline Ward / Unit Survey & $\begin{array}{l}\text { 4.1 Staff MSD Survey } \\
\text { 4.2 Staff Well-Being Survey } \\
\text { 4.3 Staff PH Survey } \\
\text { 4.4 Patient Survey }\end{array}$ & $\begin{array}{l}\text { Individual staff questionnaire } \\
(4.1,4.2,4.3)\end{array}$ \\
& Patient interview (4.4) \\
\hline
\end{tabular}

\subsubsection{Data Collection Tool - SCS}

The SCS is a one page questionnaire. The original contains 19 questions, with one question separated into 3 subsections, and uses a 5-point Likert scale to measure respondents’ attitudes about various aspects of patient safety (Wisniewski et al 2007). The 19 questions include those addressing perceptual judgements of patient safety climate, leadership, supportive work environments and communication channels. The SCS is provided as a free source from the University of Texas website; the methods of use were confirmed by the University of Texas. Demographic data were not required and were removed. The nineteen questions were slightly modified to: 1) exchange Physician for Medical, 2) remove a subsection of question 14 related to Pharmacy Leadership, and 3) exchange medical to nursing team. The SCS questionnaire was distributed with the staff PH survey (4.3) of the TROPHI data set to all staff. Four calculations were derived from these data (Institute for Healthcare Improvement, 2012): Overall Mean (OM), as the average of all 19 questions score (0-5); Safety proportion of respondents showing positive perception of 7 questions in SCS.

\subsection{Ethical approval}

Ethical approval was granted from the Loughborough University Ethics Committee and the host organisation. Verbal consent was collected from all participants involved. Data storage followed the regulatory guidance. 
The researcher (CM) processed and calculated the SCS results. The researcher coded TROPHI data and the developer (MF) completed the TROPHI calculations and analysis. The quantitative data from TROPHI and SCS produced scores indicating the risks and climate in the organisation. Descriptive statistics and Spearman's Rank Correlation were used to analyse the results. The researcher (CM) obtained additional data by contacting the relevant representatives of the organisation's management Resources.

\begin{tabular}{lllllllll}
\hline & A & B & C & D & E & F & Total & Mean \\
\hline Delivered & 21 & 25 & 26 & 30 & 30 & 27 & 159 & 26.5 \\
\hline Returns & 18 & 17 & 17 & 17 & 18 & 10 & 97 & 16.2 \\
\hline \% returns & 85.7 & 68 & 65.4 & 56.7 & 60 & 37 & 61 & 62.0 \\
\hline
\end{tabular}
reporting positive safety climate $(\%+v e)$ are indicated as percentages.

\section{Findings}

Full data sets were recorded from all sites. The response rates for the sites varied (Table 3).

Table 3 Response rates

The number of responses affected some data for inclusion. TROPHI requires 50\% response for inclusion (Fray 2010) and SCS requires 65\% return (IHI, 2012) against the staff numbers in the unit. Data from location $\mathrm{F}$ was omitted from the statistical analysis. Investigation of the staff work programmes showed some staff were unavailable during the trial in locations $\mathrm{D}$ and $\mathrm{E}$, and these absences raised the percentage return above the $65 \%$ for inclusion.

\subsection{SCS Scores}

The scores for the SCS are indicated in Table 4. Overall Mean (OM) and Safety Climate Mean (SCM) are averaged from Likert scales (0-5) and the Total Safety Climate Score (SCS) and \% 


\begin{tabular}{llllllll}
\hline Ward & A & B & C & D & E & F & Mean \\
\hline OM & 3.8 & 3.8 & 4.1 & 3.1 & 3.6 & 4.1 & 3.8 \\
\hline SCM & 3.9 & 3.9 & 4.3 & 2.6 & 3.7 & 3.8 & 3.7 \\
\hline SCS & 73.4 & 74.7 & 82.9 & 40.4 & 66.7 & 70.5 & 68.1 \\
\hline \%+ve & 43.7 & 63.6 & 87.5 & 0 & 25 & 50 & 45.0 \\
\hline
\end{tabular}

Trends of the different SCS scores can be seen in the graphs below:
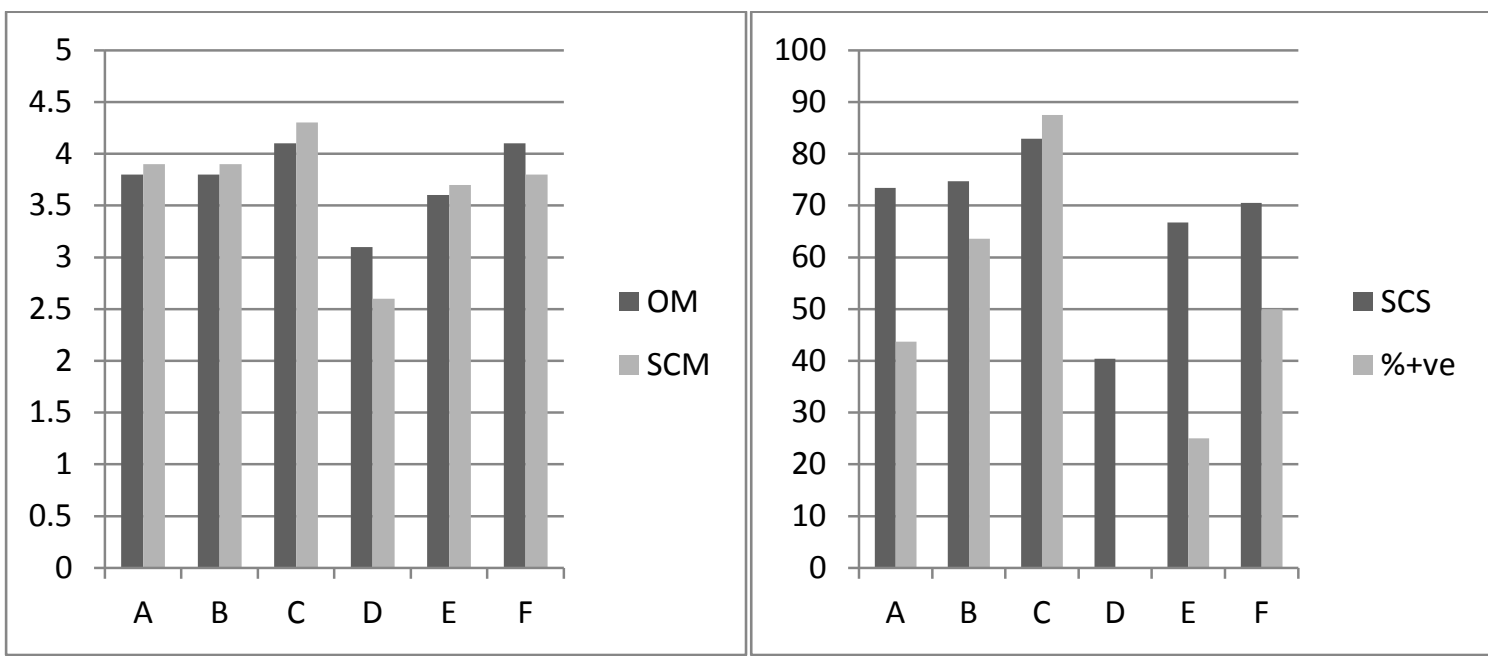

Figure 3 SCS Scores for Wards A-F

Across the different scores derived from the survey data it can be seen that the staff's perception of

safety climate showed some agreement i.e. location C scoring high in all sections and location D not

so. No respondents on Ward D reported a positive perception of safety climate (\%+ve).

\subsection{TROPHI Scores}

The total TROPHI Scores (100\%) are shown in Figure 4

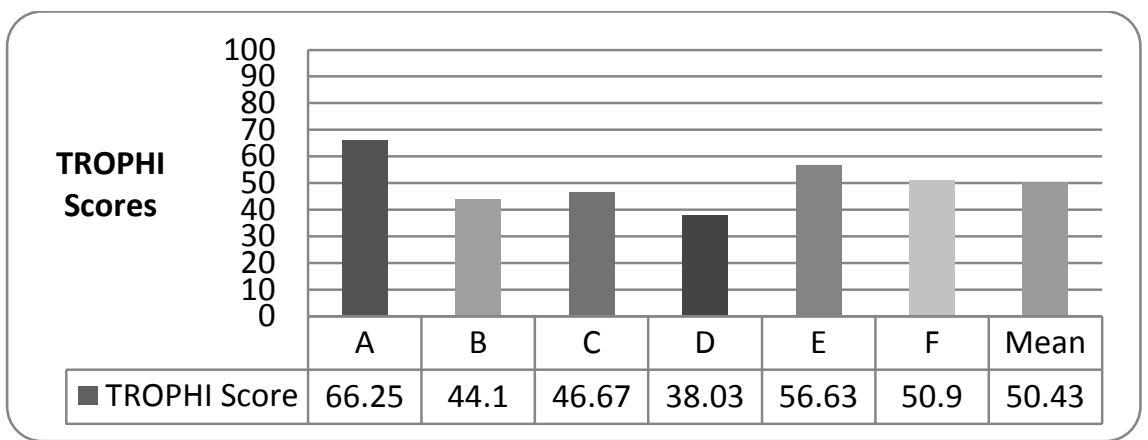

Figure 4. Total TROPHI Scores 
361

Table 5. Section Scores for TROPHI (\%). ND indicates that no data were available on the ward during the survey

\begin{tabular}{llllllll}
\hline Ward & A & B & C & D & E & F & Mean \\
\hline 1 Safety Climate & 52.6 & 40.8 & 55.0 & 24.4 & 42.4 & 56.8 & 45.3 \\
& & & & & & & \\
\hline 2 MS Health & 62.5 & 80.9 & 60.2 & 27.9 & 56.9 & 77.5 & 61.0 \\
\hline 3 Competence & 61.1 & 38.7 & 64.2 & 62.5 & 61.7 & 59.9 & 58.1 \\
\hline 4 Absence & 100 & ND & ND & ND & 99.9 & ND & 99.9 \\
\hline 5 Quality care & 89.0 & 92.0 & 87.5 & 87.5 & 95.0 & 95.0 & 91.0 \\
\hline 6 Incidents & 100 & 15.9 & 0 & 35.2 & 33.3 & ND & 36.9 \\
\hline 7 Psychological well-being & 73.3 & 77.1 & 80.3 & 64.7 & 78.0 & 78.0 & 75.2 \\
\hline 8 Patient Condition & 76.4 & 64.7 & 66.9 & 59.2 & 62.3 & 80.6 & 68.3 \\
\hline 9 Patient Perception & 100 & 62.5 & 68.5 & 88.3 & 77.8 & 100 & 79.5 \\
\hline 10 MSD Exposure & 0 & 29.2 & 0 & 0 & 0 & 0 & 4.9 \\
\hline 11 Patient Injuries & 100 & ND & 100 & ND & 45.6 & 81.8 & 90.9 \\
\hline 12 Financial & 100 & 100 & 100 & 100 & 100 & 100 & 100
\end{tabular}

Previous research (Fray and Hignett, 2013) indicated default settings for these areas to allow scores to be inserted ( $0 \%$ or $100 \%)$. These default scores have been established to fully represent the performance scores where possible. For example, a nil response from the patient survey (4.4) in a dementia ward should not be negatively (100\%) scored but not having access to musculoskeletal absence data would indicate a lack of control over this important issue for $\mathrm{PH}$ and would be scored negatively (0\%). For the purpose of the correlation analysis these default settings were not included.

4.3 Statistical Analysis Spearman's Rank Order Correlation (Gauthier 2001) was selected to evaluate the level of association between the two sets of scores. Due to gaps (ND) in data, several TROPHI sections were eliminated 

outcomes). Table 6 shows the Correlation Coefficients when comparing the ranked orders of TROPHI totals and sections against the different sections from SCS.

Table 6 Spearman's Correlation Coefficients $\left(\mathrm{n}=5, \mathrm{df}=3, \mathrm{p}<0.05^{* *}\right)$

\begin{tabular}{lllll}
\hline & OM & SCM & SCScore & \% +ve \\
\hline TROPHI Total & $\mathbf{0 . 5 0}$ & $\mathbf{0 . 2 0}$ & $\mathbf{0 . 2 0}$ & $\mathbf{0 . 2 0}$ \\
\hline 1 Safety Climate & $0.90^{* *}$ & 0.70 & 0.70 & 0.70 \\
\hline 2 MS Health Measure & 0.60 & 0.70 & 0.70 & 0.70 \\
\hline 3 Competence and Compliance & 0.10 & 0.00 & 0.00 & 0.00 \\
\hline 5 Quality of Care & -0.21 & -0.10 & -0.10 & -0.10 \\
\hline 7 Psychological well-being & 0.60 & 0.70 & 0.70 & 0.70 \\
\hline 8 Patient Condition & $0.90^{* *}$ & 0.70 & 0.70 & 0.70 \\
\hline 9 Patient Perception & -0.20 & -0.60 & -0.60 & -0.60 \\
\hline
\end{tabular}

Correlation analysis with only 5 sets of ranked pairs can only be interpreted as indicative of the links between the data sets. The TROPHI measures of Safety Climate and Patient Condition showed significant correlation $(\mathrm{p}<0.05)$ with the SCS overall mean $(\mathrm{OM})$. Safety Climate, MS Health Measures, Psychological Well-being and Patient Condition showed strong positive correlation across all measures of the SCS data but were not significant. The authors of the SCS tool suggested that relationships with the \% Total SCS and the \% positive scores are more important. Though the sample was small (number of wards $=6$ ), the relationships between the different safety climate and performance scores collected in this case study showed good agreement in several areas.

\section{Discussion}

The findings from our study using two different measurement tools revealed a set of interesting relationships between the sources of the data and actual measures of performance. These relationships support the use of the meso-ergonomics framework (Karsh et al., 2014) and suggest that Survey (Institute for Healthcare Improvement, 2012) shares similarities with other climate measures (Halligan and Zecevic, 2011) in that it requires a cohort of people employed within the work site to 
safety behaviour). TROPHI (Fray and Hignett, 2013) likewise collects the perceptions of safety climate and patient handling performance from a wide cohort of employees and is comparable to the SCS, but TROPHI is also supplemented by other sources and information from a wide range of sources. Organisational outcome data describe the level of MSD and the costs associated with those losses, patient perceptions indicate the quality of service delivered from a patient handling perspective. The specific measure of safety climate within the TROPHI tool includes the perception of staff through an indication of management commitment to patient handling safety but also records the component parts of the system for implementing the management of patient handling risk (e.g. risk assessments, communication and documentation systems). The interaction of the physically observed systems components against the perception judgements show interesting comparisons in the data collected.

Despite the limitation of using data from only 6 wards there were encouraging correlations between the data from the two methods. The SCS method collected subjective data through the evaluation of the staff opinion which relates very clearly to the sections of TROPHI that also collected data through staff perceptions and the observed components of a successful management system. Safety Climate (1) correlated closest with the SCS OM to show that similar values and perceptions were measured. Other positive correlations appeared with MS Health Measures (2), Psychological Well-being (7), and Patient Condition (8), and all these are strongly influenced by staff perception and the data collected through the TROPHI Staff Survey $(4.1,4.2,4.3)$.

A different effect was seen between SCS scores and the observed data in Competence and Compliance (3), where there was no correlation. The measure of competence and compliance is an observational score based on agreement with best practice for patient transfers (Johnsson et al., 2004). Quality of Care (5) and Patient Perception (9), which collected data from the patient surveys, showed poor association. These results are of particular concern as an underlying belief of climate measures is that positive climate leads to safe behaviour. Closer investigation of the raw data for Competence 
and Compliance (3) showed in location B that one individual's poor performance influenced the ward score and conditions or selection criteria may need to be reviewed in future trials. The level of competence and compliance may be affected by other factors e.g. the level of provision of equipment/ safe environments was shown to be poor in all wards (TROPHI Section 10), though good levels of lifting devices were recorded the control of bathing and other risks was poor. This lack of association between the measures of safety climate by documentation and communication channels is repeated in a wider evaluation of TROPHI data sets (Fray et al, 2014).

As a relatively small study ( $\mathrm{n}=6$ locations, $\mathrm{n}=97$ participants) there are certain restrictions on the analysis presented. The response rate averaged 62 percent from survey participants and the rate from location F was particularly low. Response rate limits imposed by TROPHI and SCS were not met in location F. Further analysis is required to examine the reasons for reduced response in F.

Specifically, clearer strategies may need to be adopted to ensure higher levels of return to ensure inclusion on rate of return.

\subsection{Investigating the micro-macro relationship.}

The findings have shown some effects which suggest the sources of the data collected within the different tools may reveal some of the relationships between the scores. The data from SCS were all represented by combination scores of the staff survey. The full range of 19 questions recorded individual perceptions of the performance of the organisation for safety attitudes, communication, leadership and the priority placed on reporting and management of risks. OM included all responses ( $\mathrm{n}=19$ questions) but SCM, SCS and \% positive used a specific selection of responses ( $\mathrm{n}=7$ questions) from the total. All these scores represent the collective group perception of the attitudes of the unit towards safety and are suggestive of the macro ergonomics quality of safety culture.

Table 7 Content and sources of TROPHI and SCS data 


\begin{tabular}{|c|c|c|c|}
\hline $\begin{array}{l}\text { TROPHI } \\
\text { Sections }\end{array}$ & Outcome and source & SCS & $\begin{array}{l}\text { Outcome and } \\
\text { Source }\end{array}$ \\
\hline 1 Safety Culture & $\begin{array}{l}\text { Audit of safety systems } \\
\text { Objective checklist of systems in place } \\
\text { Perception of management commitment }\end{array}$ & \multirow[t]{3}{*}{ Overall mean } & \multirow{3}{*}{$\begin{array}{l}\text { Perception of } \\
\text { Safety Climate } \\
\text { Staff survey } \\
\text { (19 questions) }\end{array}$} \\
\hline 2 MS health & $\begin{array}{l}\text { MSD level in staff } \\
\text { Staff survey of MS health }\end{array}$ & & \\
\hline $\begin{array}{l}3 \text { Competencel } \\
\text { Compliance }\end{array}$ & $\begin{array}{l}\text { PH Observation and documentation } \\
\text { Observed information by assessor } \\
\text { Compliance with documented plan }\end{array}$ & & \\
\hline $\begin{array}{l}4 \text { Absence or } \\
\text { staff health }\end{array}$ & $\begin{array}{l}\text { MSD absence records } \\
\text { Organisations absence records }\end{array}$ & \multirow[t]{3}{*}{$\begin{array}{l}\text { Safety Climate } \\
\text { Mean }\end{array}$} & \multirow{3}{*}{$\begin{array}{l}\text { Perception of } \\
\text { Safety Climate } \\
\text { Staff survey } \\
\text { (7 questions) }\end{array}$} \\
\hline $\begin{array}{l}5 \text { Quality of } \\
\text { care }\end{array}$ & $\begin{array}{l}\text { Patient perception of PH care } \\
\text { Patient Survey }\end{array}$ & & \\
\hline $\begin{array}{l}6 \text { Accident } \\
\text { numbers }\end{array}$ & $\begin{array}{l}\text { Accident No. and non-reporting ratios } \\
\text { Organisational records } \\
\text { All staff perception of recording rate }\end{array}$ & & \\
\hline $\begin{array}{l}7 \text { Psychological } \\
\text { well being }\end{array}$ & $\begin{array}{l}\text { Worker well-being } \\
\text { Staff perception of wellbeing }\end{array}$ & \multirow[t]{3}{*}{$\begin{array}{l}\text { Safety Climate } \\
\text { Score }\end{array}$} & \multirow{3}{*}{$\begin{array}{l}\text { Perception of } \\
\text { Safety Climate } \\
\text { Staff survey } \\
\text { (7 questions) }\end{array}$} \\
\hline $\begin{array}{l}8 \text { Patient } \\
\text { condition }\end{array}$ & $\begin{array}{l}\text { Effective management of clinical need } \\
\text { All staff perception of effectiveness }\end{array}$ & & \\
\hline $\begin{array}{l}9 \text { Patient } \\
\text { perception }\end{array}$ & $\begin{array}{l}\text { Patient responses to } \mathbf{P H} \text { actions } \\
\text { Patient survey after } \mathrm{PH} \text { tasks }\end{array}$ & & \\
\hline $\begin{array}{l}10 \mathrm{MSD} \\
\text { exposure } \\
\text { measures }\end{array}$ & $\begin{array}{l}\text { Workload from PH tasks } \\
\text { Assessor review of PH demands on the } \\
\text { workforce }\end{array}$ & \multirow[t]{3}{*}{$\begin{array}{l}\text { \% reporting } \\
\text { positive safety } \\
\text { climate }\end{array}$} & \multirow{3}{*}{$\begin{array}{l}\text { Perception of } \\
\text { Safety Climate } \\
\text { Staff survey } \\
\text { (7 questions) }\end{array}$} \\
\hline $\begin{array}{l}11 \text { Patient } \\
\text { injuries }\end{array}$ & $\begin{array}{l}\text { Recorded patient injuries from PH } \\
\text { Organisational records }\end{array}$ & & \\
\hline 12 Financial & $\begin{array}{l}\text { Calculation of costs versus investment } \\
\text { Financial records }\end{array}$ & & \\
\hline
\end{tabular}

Table 7 identifies the information collected in each of the TROPHI section and the SCS. The

TROPHI data collection has several different collection methods and we see different levels across the micro to macro-ergonomics perspective. The safety culture score (1) identified both the microergonomics items form the objective recording of the communications in place but also added the overall macro measure of the collective perception of management commitment. Some sections included across levels and some single sources. In addition there were differences around the level within the organisation that sources reflected. Patient reflections were recorded for quality of care (5) and patient perception (9), where the group perceptions from staff were included for safety culture (1), MS health (2), Accident data (6), Psychological well-being (7) and patient condition (8). Objective measures of actual events were represented by safety culture (1), competence and compliance (3), 
MSD absence (4), accident numbers (6), MSD exposure (10), patient injuries (11) and financial review (12). These levels of data representing the micro, macro or across levels data may in part explain some of the links between the scores in the case study.

Figure 5 represents the data collection as a function of the micro to macro ergonomics levels. It can be seen that the sections representing the clearest links are measures at the same level within the al., 2014) to concentrate the investigation on the relationships across the range of possible measures. micro-macro scale. More easily the lack of relationship can be seen across the boundaries of both level and source. For example, patient data at a micro level as a review of physical activities in quality of care (5) and patient perception (9) showed no relationship with the macro data of the SCS. Information provided by the external assessor in competence and compliance (3) and MSD workload (10) also showed poor relationships with the SCS scores. The requirements for possible inclusion of a range of objective and multi-level data in the measure of safety performance or climate (Flin, 2007) is discussed in the following section but these relationships support the use of this framework (Karsh et 
Figure 5 The micro macro relationships identified in the case study

\begin{tabular}{|l|l|l|}
\hline $\begin{array}{l}\text { TROPHI } \\
\text { Sections }\end{array}$ & Outcome and source \\
\hline 1 Safety Culture & $\begin{array}{l}\text { Audit of safety systems } \\
\text { (Micro and Macro) }\end{array}$ \\
\hline 2 MS health & $\begin{array}{l}\text { MSD level in staff } \\
\text { Macro }\end{array}$ \\
\hline $\begin{array}{l}\text { 3 Competence/ } \\
\text { Compliance }\end{array}$ & $\begin{array}{l}\text { PH Observation and documentation } \\
\text { Micro } \\
\text { 4 Absence or } \\
\text { staff health }\end{array}$ & $\begin{array}{l}\text { MSD absence records } \\
\text { Macro }\end{array}$ \\
\hline $\begin{array}{l}\text { 5 Quality of } \\
\text { care }\end{array}$ & $\begin{array}{l}\text { Patient perception of PH care } \\
\text { Patient Micro }\end{array}$ \\
\hline $\begin{array}{l}\text { 6 Accident } \\
\text { numbers }\end{array}$ & $\begin{array}{l}\text { Accident No. and non-reporting ratios } \\
\text { Macro }\end{array}$ \\
\hline $\begin{array}{l}7 \text { Psychological } \\
\text { well being }\end{array}$ & $\begin{array}{l}\text { Worker well-being } \\
\text { Macro } \\
\text { Overall mean } \\
\text { (Macro) }\end{array}$ \\
\hline $\begin{array}{l}\text { 8 Patient } \\
\text { condition }\end{array}$ & $\begin{array}{l}\text { Effective management of clinical need } \\
\text { Macro }\end{array}$ \\
\hline $\begin{array}{l}\text { 9 Patient } \\
\text { perception }\end{array}$ & $\begin{array}{l}\text { Patient responses to PH actions } \\
\text { Patient Micro }\end{array}$ \\
\hline $\begin{array}{l}\text { 10 MSD } \\
\text { exposure } \\
\text { measures }\end{array}$ & $\begin{array}{l}\text { Workload from PH tasks } \\
\text { Micro }\end{array}$ \\
\hline $\begin{array}{l}\text { 11 Patient } \\
\text { injuries }\end{array}$ & $\begin{array}{l}\text { Recorded patient injuries from PH } \\
\text { Macro }\end{array}$ \\
\hline $\begin{array}{l}\text { 12 Financial } \\
\text { Calculation of costs versus investment } \\
\text { Macro review }\end{array}$ \\
\hline
\end{tabular}

Thick Lines= Significant links between TROPHI and SCS (Spearmans Rho p<0.05)

Thin Lines $=$ Suggestive links between TROPHI and SCS (Spearmans Rho N.S.=0.7-0.9).

\subsection{Towards a model of 'patient handling climate'}

The results and comparison within this case study informs a wider consideration of the measures and evaluation of the qualities contributing to safety behaviour and climate within healthcare settings.

The reliance on a cohort's perception of safety, records only one single contextual dimension of a multi-dimensional interactive system. The questions raised from this data concern the differences between the data and source across the micro and macro ergonomics level, specifically between the observations of patient transfers from the competence and compliance measures compared with the SCS scores. Secondly, it suggests that there is a requirement to explore measures across the intervention and outcome range for occupational situations (Robson et al, 2007) and that recording 
what systems or actions are observed in the organisation will allow clear comparison with the employee's perceptions of the same. Finally, the findings would suggest that there is benefit in the consideration of data from all levels affected by the climate presentation. In many occupational systems those levels may be restricted to the organisational level and the effects on staff. The healthcare application explored in this study suggests that organisational, manager/supervisor, staff and patients may all have a valid input to the overall picture. An overview of the areas that contribute to the measurement of safety climate for this specific patient handling application is suggested in Figure 6 below.

Observed Intervention Measures. Communication systems, supervision, education and training, safe equipment and environments

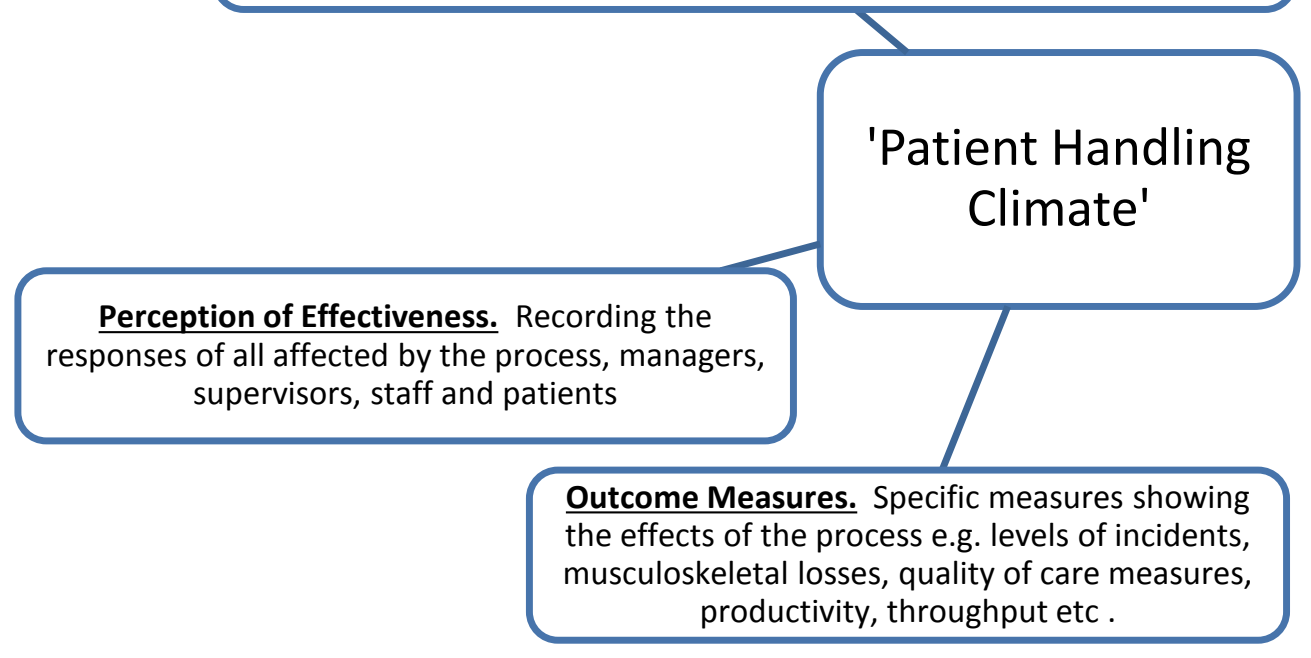

Figure 6. Contributing Factors to 'Patient Handling Safety Climate'

Observing the measure of climate in this form suggests that the perception values utilised in many previous climate tools are only one contributing factor to the overall combination of factors. It may also be considered that these three factors map the micro, macro, meso ergonomics framework. Observed intervention measures in many situations equate to micro-ergonomics physical workplace changes that are observed and should model industry best practice. Many of the outcome measures 
are in the domain of organisational performance and represent the wider macro-ergonomics feedback. The perception of effectiveness values are representative of an individual's review of the operational systems in place so may well act as the meso-ergonomics link between the intervention and outcome levels. The data in this case study have explored the underlying assumption that good organisational climate is directly indicative of good safety performance. The evidence supported this in part, but the lack of correlation with specific objective measures especially in the delivery of patient transfers is a concern and should be further investigated.

\subsection{Summary, future work and next steps}

In this paper we used the Karsh et al. (2014) framework to probe deeper into the relationship between two domains within healthcare human factors and ergonomics, namely patient handling and safety climate. In many respects, our findings raised more questions than provided answers to some of the relationships which may exist between these two areas of research and practice. Such an approach toward scientific inquiry is very much in line with Wilson’s (2014) statement about the need to simultaneously address multiple system levels and adopt a multidisciplinary approach towards study design, analysis and interpretation. The value of the framework was that it helped to structure these activities and prompt a set of further questions to be answered. An example outcome from using the framework was to posit the existence of a new construct, 'patient handling climate', the aim of which is to bring together phenomena traditionally separated out into aspects of micro- and macroergonomics. The physical risks of the individual carer actions and choices to physically move a patient with or without devices or using different methods or techniques illustrate the influences at a focussed micro ergonomics level. Errors of judgement and completion at this level can be clearly linked with specific outcomes and physical measures of practice (e.g. injury or accident numbers). Those individual actions are clearly influenced by the organisational systems for supporting safe behaviour, education, supervision, equipment purchasing strategies etc. Recent publications show that there is positive impact on reducing risks from patient handling (Burdorf et al., 2013) but the most successful controls depend on the inclusion of micro, macro and mesoergonomics systems to 
44

support the improvements (Thomas and Thomas, 2014 in press). Quantifying and clarifying this relationship reliably remains a future challenge across a range of occupational ergonomics investigations.

In our future work we plan to return to the study site and increase the number of locations and thereby provide more detail and volume for the analysis. This would allow further investigation of the relationships between the various performance measures and move us a step closer to an unpacking the components of 'patient handling climate' and its relationship to a range of outcome measures. 


\section{References}

Alexander, P. 2011. A systems approach to safer handling practice. Chapter 5. In Smith, J. (Ed.). The Guide to The Handling of People. A Systems Approach (6 $6^{\text {th }}$ Ed.). Teddington, Middlesex: BackCare. pp63-72.

Alvarado, C.J. (2012), Human factors and ergonomics in infection prevention. In P. Carayon (Ed.), Handbook of Human Factors and Ergonomics in Health Care and Patient Safety. Boca Raton: CRC Press.

ANA (2012) Safe patient handling and mobility. Interprofessional National Standards, ANA, USA

Burdorf A., Koppelaar E., Evanoff B., (2013). Assessment of the impact of lifting device use on low back pain and musculoskeletal injury claims among nurses. Occupational and Environmental Medicine 2013; 70: 491-497

Carayon P., (Ed) 2012. Handbook of Human Factors and Ergonomics in Health Care and Patient Safety. CRC Press

Carayon, P. 2006. Human factors of complex sociotechnical systems. Applied Ergonomics, 37(4), pp.525-535.

Flin, R. 2007. Measuring Safety Culture In Healthcare: A Case For Accurate Diagnosis. Safety Science, 45(6), pp.653-667.

Fray, M. 2010. A comprehensive evaluation of outcomes from patient handling interventions. PhD Thesis. Loughborough University.

Fray M. and Hignett, S. 2013. TROPHI: Development of a tool to measure complex, multi-factorial patient handling interventions. Ergonomics DOI: 10.1080/00140139.2013.807360 (online) 
Fray M., Hignett S., Munro C., and Cunningham C., (2014). A detailed analysis of factors associated with performance in patient handling interventions (TROPHI). Proceedings of the AHFE Conference, Krakow Poland July 2014

Gauthier, T.D. 2001. Detecting Trends Using Spearman's Rank Correlation Coefficient. Environmental Forensics, 2, pp.359-362.

Guldenmund, F. W. (2000). The nature of safety culture: a review of theory and research. Safety Science, 34, (1-3), 215-257.

Halligan M and Zecevic A. Safety culture in healthcare: a review of concepts, dimensions, measures and progress. BMJ: Quality and Safety, 2011, 20, 338-343

Holden, R.J. Carayon, P., Gurses, A.P., Hoonakker, P., Hunt, A.S, Ozok, A.A. and Rivera-Rodriguez, A.J., (2013, in press), SEIPS 2.0: a human factors framework for studying and improving the work of healthcare professionals and patients. Ergonomics.

IEA. (2000). What is ergonomics? Retrieved January 31, 2009, 2009, from http://www.iea.cc/browse.php?contID=what is ergonomics

Institute for Healthcare Improvement. 2012. Safety Climate Survey. Institute for Healthcare Improvement. The Centre of Excellence for Patient Safety Research and Practice. University of Texas, Austin, Texas, USA. http://w.primaris.org/sites/default/files/resources/Patient\%20Safety/safety\%20climate\%20survey.p df [Accessed 29 July 2012].

Itoh. K., Andersen, H.B. and Madsen, M.D. (2012), Safety culture in health care. In P. Carayon (Ed.), Handbook of Human Factors and Ergonomics in Health Care and Patient Safety. Boca Raton: CRC Press.

ISO (2012) TR12296 Ergonomics: Manual handling of People in the Healthcare Sector. 2012 ISO Geneva.

Johhnsson, C., Kjellberg K., Kjellberg, A., Lagerstrom, M., 2004. A direct observation instrument for assessment of nurses’ patient transfer technique (DINO). Applied Ergonomics, 35, 591-601. 
Karsh, B. (2006). Meso-ergonomics: a new paradigm for macroergonomics research. Paper presented at the Proceedings of the International Ergonomics Association 2006 Congress, Maastricht.

Karsh B., Waterson P., Holden R. 2014 . Crossing the levels in systems ergonomics: A framework to support 'mesoergonomic' inquiry. Applied Ergonomics 45 (2014) 45-54

Karsh, B.-T., Weinger, M.B., Abbott, P.A., Wears, R.L., 2010. Health information technology: fallacies and sober realities. Journal of the American Medical Informatics Association, (JAMIA) 17, 617e623.

Knibbe, J., Friele, R., 1999. The use of logs to assess exposure to manual handling of patients, illustrated in an intervention study in home care nursing. International Journal of Industrial Ergonomics, 24, 445-454.

Ko, M. amd Bindman, A.B. (2013, in press), No man is an island: disentangling multilevel effects in health services research. BMJ: Quality and Safety.

Marras, W., Davies, K., Kirking, B., Bertsche, P., 1999. A comprehensive analysis of low-back disorder risk and spinal loading during the transferring and repositioning of patients using different techniques, Ergonomics 42 (7), 904-926.

Munro C., Fray M., Hignett S., and Waterson P.E. (2013) Measuring patient handling safety culture: a comparison of two methods. Column: Nov 2013, NBE, UK.

NBE (2010) Standards in manual handling. ( $3^{\text {rd }}$ Edition) NBE, Towcester, UK.

Nelson, A., Collins, J., Siddarthan, K., Matz, M., Waters, T., 2008. Link between safe patient handling and patient outcomes in long term care. Rehabilitation Nursing, 33 (1), 33-43.

Nelson, A., Matz, M., Chen, F., et al. 2006. Development and evaluation of a multifaceted ergonomics program to prevent injuries associated with patient handling tasks. International Journal of Nursing Studies, 43 (6), 717-733.

Nieva, V.F. and Sorra J. (2003), Safety culture assessment: a tool for improving patient safety in organizations. Quality and Safety in Healthcare, 12 (Suppl. II), ii17-ii23. 347-353. 
Robson, L.S., Clarke, J.A., Cullen, K., et al. (2007) The effectiveness of occupational safety management system interventions: A systematic review. Safety Science, 45, 329-353.

Sexton, J.B., Helmreich, R.L., Neilands, T.B., Rowan, K., Vella, K., Boyden, J., Roberts, P.R., Thomas, E.J. 2006. The Safety Attitudes Questionnaire: psychometric properties, benchmarking data, and emerging research. BMC Health Services Research 6, pp44-52.

Smith, J. (Ed.). The Guide to The Handling of People. A Systems Approach ( $6^{\text {th }}$ Ed.). Teddington, Middlesex: BackCare. pp63-72.

Thomas D. amd Thomas Y., (2014 in Press) Interventions to reduce injuries when transferring patients: A critical appraisal of reviews and a realist synthesis. International Journal of Nursing Studies

Trinkoff, A., Johantgen, M., Storr, C., Gurses, A., Liang Y., Han K. (2011). Linking nursing work environment and patient outcomes. J. Nurs. Regul. 2,10-16

Vincent, C., S. Taylor-Adams, and N. Stanhope. (1998) Framework for Analysing Risk and Safety in Clinical Medicine. British Medical Journal 316: 1154-1157.

Waterson, P.E. (2014), Health information technology and sociotechnical systems: a progress report on recent developments within the UK National Health Service (NHS). Applied Ergonomics, 45, 2, 150-161.

Waterson, P. (2009), A critical review of the systems approach within patient safety research. Ergonomics, 52(10), pp.1185-1195.

Wilson, J.R. (2014), Fundamentals of systems ergonomics/human factors. Applied Ergonomics, 45, 513.

Wisniewski, A.M., Erdley, W.S., Singh, R., Servoss, T.J., Naughton, B.J., Singh, G. 2007. Assessment of Safety Attitudes in a Skilled Nursing Facility. Geriatric Nursing, 28(2), pp.126136. 
680 World Health Organization (WHO) (2013), Patient safety - organizational tools. 681 http://www.who.int/patientsafety/research/methods_measures/human_factors/organizational_tools/ 682 en/(last accessed 14th July, 2013) 


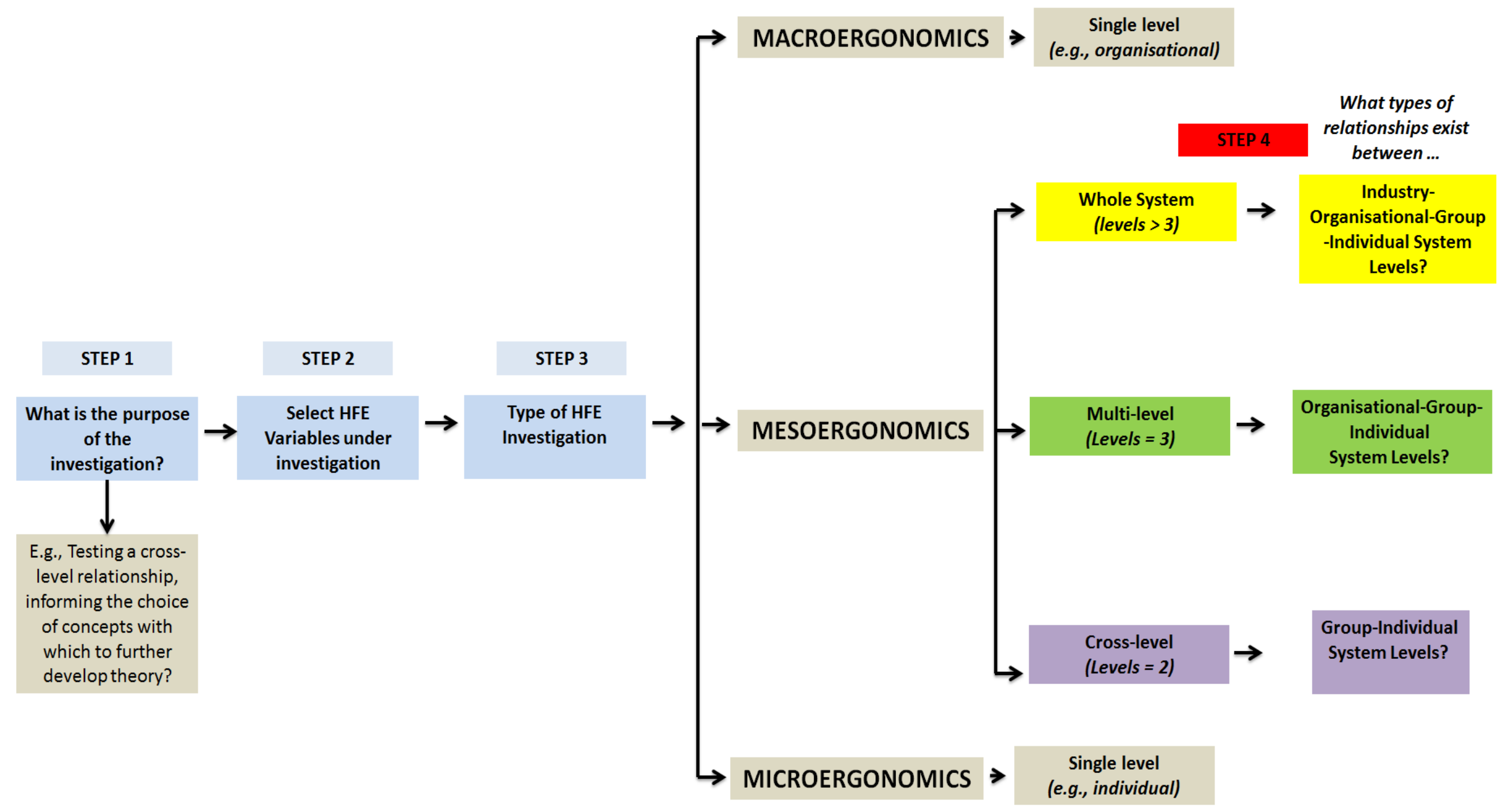




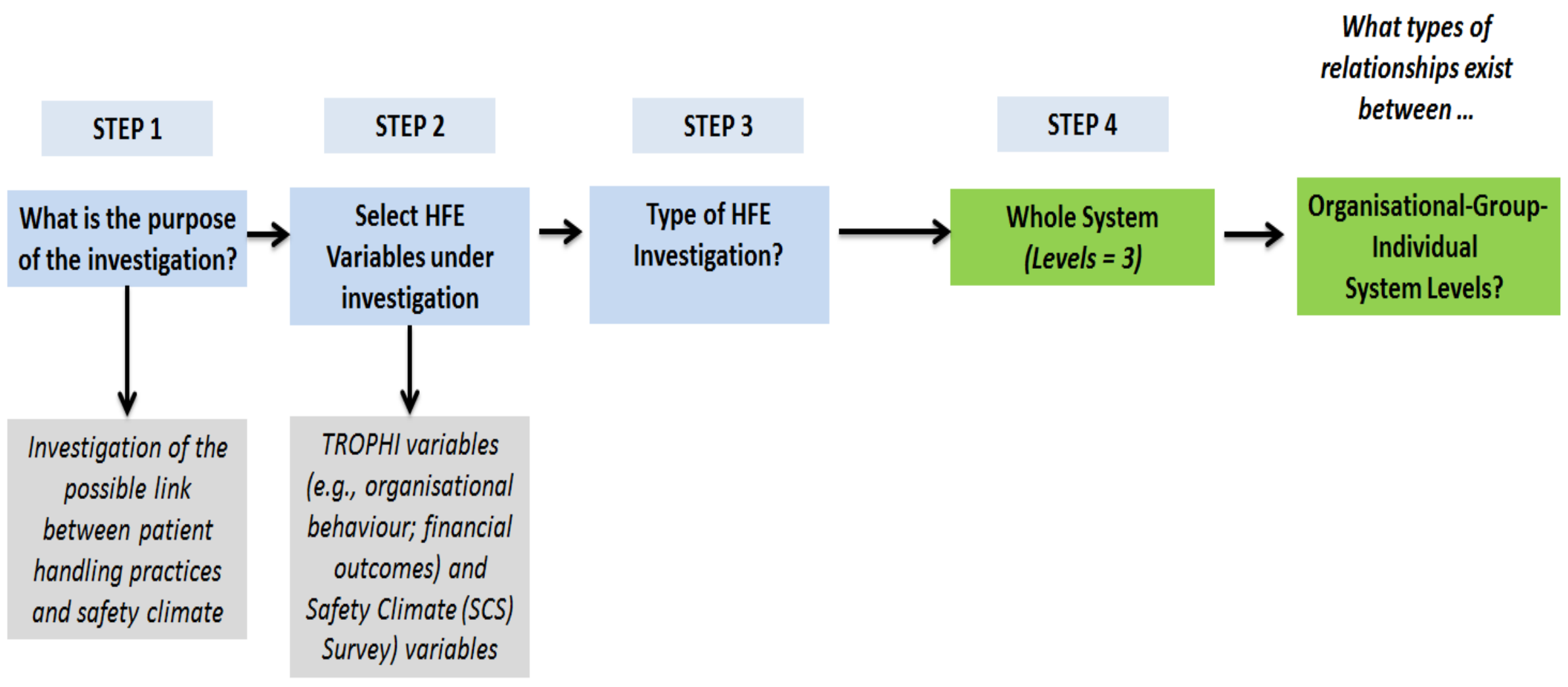

